What then can be done? The B.M.A. is seeking an immediate meeting with the Secretary of State for Education and Science to ask him to reverse the unjust discrimination against clinical teachers. A national meeting of medical teachers will be called to discuss the Secretary of State's reply. But a long-term solution is also needed. Professor P. O. Yates (B.M.F., 17 September, p. 709) pointed out that universities have long accepted that their staff could receive fees in addition to their salaries for consultant and other work done for outside bodies provided such work is relevant to their own research. If doctors who are university teachers weré paid additional fees for their clinical duties by the N.H.S., their earnings could be at least equal to those of their hospital colleagues. This seemingly common-sense solution may be reached only if the teachers have a negotiating body which has a right of access to the U.G.C. as well as to the Ministries. The B.M.A. is suited to this role.

\section{Burst Abdomen}

Thirty years ago the incidence of complete dehiscence of abdominal incisions was about $1 \%{ }^{1}$ Today the figure is much the same. ${ }^{2-5}$ This is not surprising; for methods of suturing the abdominal wall have not changed, and there is still no known method of promoting healing of incisions. Any improvement in this field that might have been expected from advances in the management of patients before and after operation has been balanced by the rise in the number of major operations carried out on elderly patients and on patients who have been treated with corticosteroids-for both groups are known to be at risk.

The condition may occur at any age, but is most common in the elderly. It happens more often to men than women, usually takes place in the second week, with its peak at the tenth post-operative day, is twice as common in winter as in summer, ${ }^{3}$ and has a mortality of around $20 \%{ }^{6}$ Most deaths occur in patients on whom an operation has been performed for a major illness. Thus half of the fatal cases in the series reported by $\mathrm{G}$. Efron ${ }^{2}$ had advanced malignant disease. But there is no doubt that in other patients disruption of the wound is the final factor which tips the scales against their chances of survival.

In at least half of the cases of burst abdomen more than one predisposing factor may be found. Before he is taken to the theatre it is known that the patient has a higher risk of dehiscence of his wound if he is being treated with corticosteroids, or if he has a pre-existing cough, abdominal distension, protein or vitamin $\mathrm{C}$ depletion, or uraemia. At operation, faulty technique or poor suture material may be blamed. After surgery, an excessive rise of abdominal pressure from straining, coughing, vomiting, distension, or hiccup, pancreatic or intestinal digestion of the suture line from a fistula, or local infection, haematoma, or ischaemia are all factors of considerable importance.

1 Hartzell, J. B., and Winfield, J. M., Int. Abstr. Surg., 1939, 68, 585.

2 Efron, G., Lancet, 1965, 1, 1287.

s Hampton, J. R., Brit. med. F., 1963, 2, 1032.

4 Tweedie, F. J., and Long, R. C., Surg. Gynec. Obstet., 1954, 99, 41.

s Lythgoe, J. P., Postgrad. med. 7., 1960, 36, 388.

- Mann, L. S., Spinazzola, A. J., Lindesmith, G. G., Levine, M. J., and Kuczerepa, W., F. Amer. med. Ass., 1962, 180, 1021.

- Alexander, H. C, and Prudden, J. F., Surg. Gynec. Obstet., 1966, 122, 1223.
H. C. Alexander and J. F. Prudden, ${ }^{7}$ in a recent careful study of 200 consecutive examples of burst abdomen which they compared with 200 matched laparotomies, found the common aetiological factors to be: chest complications $(24 \%)$, distension (22\%), haematoma (19\%), and wound infection (14\%). The serum albumin was low in $53 \%$ of the patients in whom it was measured, compared with $9 \%$ in the control group.

Though surgeons debate the virtues of different suture materials this seems to matter little. Indeed it is usual to find the sutures lying intact and free in the burst wound; the adjacent tissues are cut through by the sutures like cheese under a wire cutter. Alexander and Prudden stress that more important than the suture material itself is the amount of tissue incorporated within the suture, the most common error being the inclusion of too little rather than too much.

An important diagnostic pointer which should be taught to the nursing and house staff is the appearance of a pink, watery discharge through the wound a week or so after operation. This is blood-tinged peritoneal exudate escaping through the deeper layers of the wound, and its appearance is strong evidence of imminent complete dehiscence. Recognition of the significance of this discharge should make it possible to resuture the abdominal wound before the frightening and potentially dangerous complication of complete rupture is allowed to occur.

\section{Witness or Advocate?}

A judge's comment in the Court of Appeal last week, that "the doctor is a paid advocate who speaks for the person who pays his fee," will not lessen the general reluctance of medical men to give expert evidence. They must, like any expert witness, be prepared to have their opinions challenged, sometimes sharply, in cross-examination. To most this is ordeal enough, and one which would readily be avoided but for a sense of duty and a wish to aid the administration of justice. In such circumstances professional men are entitled to hope that they may be spared public discomfiture beyond what is strictly necessary to the pursuit of the proper processes of the law.

There already exists in England some of the machinery necessary for the provision of procedures which will result in both parties to a case being given an authoritative medical opinion on a neutral basis. ${ }^{2}$ Order $37 \mathrm{~A}$ of the English Rules of the Supreme Court gives the court power, on the application of a party, to appoint a court expert (not necessarily a medical expert) to inquire into and report on any question of fact or opinion. The report has to be made in writing, subject to the right of the parties to demand an opportunity to cross-examine. Apparently this machinery has been seldom used. ${ }^{3}$ It would probably be used more if the expert's fee were paid by the court rather than shared by the parties to the suit. This is what happens in the New York medical expert testimony project, ${ }^{4}$ where panels of eminent specialists have been formed, known for their skill and impartiality.

\footnotetext{
Guardian, 8 October 1966.

2 Brit. med. F., 1963, 2, 1274.

3 The Annual Practice, 1966. Sweet and Maxwell Ltd., Stevens and Sons Ltd., and Butterworth Ltd., London.

- Impartial Medical Testimony, a report by a Special Committee of the Bar Association of New York, 1956. Macmillan, New York.
} 